\title{
LAS LIMITACIONES DEL PARLAMENTO RECIÉN CONSTITUIDO DURANTE LA PRORROGATIO GUBERNAMENTAL
}

ESPERANZA GÓMEZ CORONA 
SUMARIO

I. CUESTIONES PRELIMINARES. II. EL GOBIERNO EN FUNCIONES. II.1 El Gobierno central en funciones. II.2 El Gobierno en funciones en el sistema autonómico español. III. POSICIÓN Y FUNCIONES DEL PARLAMENTO RECIÉN CONSTITUIDO DURANTE LA PRORROGATIO GUBERNAMENTAL. III.1 Organización interna de las Cámaras. a) Constitución de las comisiones parlamentarias. b) Imposibilidad de incluir asuntos en el orden del día. III.2 Funciones parlamentarias. a) Potestad legislativa. b) Función presupuestaria. c) Función de control de la acción del Gobierno. d) Función de impulso. 


\title{
LAS LIMITACIONES DEL PARLAMENTO RECIÉN CONSTITUIDO DURANTE LA PRORROGATIO GUBERNAMENTAL
}

\author{
ESPERANZA GÓMEZ CORONA* \\ Profesora Titular de Derecho Constitucional \\ Universidad de Sevilla
}

\section{CUESTIONES PRELIMINARES}

La crisis económica, política, social e institucional que España lleva arrastrando desde hace unos años ha provocado un tsunami en el panorama electoral, con la aparición de nuevas formaciones que han irrumpido con fuerza en la escena política.

Estos hechos, producidos en un país con un bipartidismo más que asentado y un sistema electoral que castiga a las formaciones que no ocupan los dos primeros puestos de la circunscripción, han provocado situaciones que sin ser totalmente nuevas ${ }^{1}$, sí se han generalizado como no lo habían hecho nunca. En esta línea, las

* Departamento de Derecho Constitucional. Facultad de Derecho. Universidad de Sevilla. C/ Enramadilla 18-20. 41071 Sevilla. España. Correo electrónico: gcorena@us.es

${ }^{1}$ En la Comunidad Autónoma Cántabra, tras la dimisión del Presidente Hormaechea el 5 de noviembre de 1994, motivado por una condena penal por prevaricación y malversación de caudales públicos, continuó en funciones casi nueve meses, hasta el 14 de julio de 1995, fecha en que fue investido el nuevo Presidente de Cantabria. Sobre este particular, puede consultarse RevirieGo Picón, F., «La regulación del gobierno en funciones en los ordenamientos autonómicos. A propósito del caso cántabro», LuCas Murillo de la Cueva, P., Gobierno y Constitución, Valencia, Tirant lo Blanch, 2005. 
elecciones autonómicas celebradas en nuestro país en 2015 - las de Andalucía el 22 de marzo y las trece CCAA que accedieron a la autonomía por la vía del 143 CE el 24 de mayo - arrojaron unos resultados que obligan a desarrollar una nueva cultura de pactos no muy asentada entre nosotros. La aparición de nuevos actores políticos, la erosión del bipartidismo y la polarización en torno a cuestiones como la unidad de España, han provocado ecuaciones imposibles, que alargan el período que media entre la celebración de elecciones y la investidura del nuevo Gobierno. Buena prueba de ello es lo sucedido en Cataluña, donde tras las elecciones del 27-S se alcanzó la investidura dos horas antes de que finalizara el plazo de dos meses desde la primera votación que marca el Estatut ${ }^{2}$.

Los mismos resultados de las generales del 20 de diciembre de 2015, son una muestra más, con un mapa en el Congreso de los Diputados que dejaba muchas opciones abiertas y que han abocado a unas nuevas elecciones generales ante la falta de acuerdo. Estos cambios repercuten en el proceso de formación del Gobierno que se alarga y complica al necesitar en ocasiones el concurso de más de dos formaciones políticas. No obstante, este período tiene un límite temporal entre nosotros: dos meses desde la celebración de la primera votación de investidura $^{3}$ o desde la constitución de la Cámara ${ }^{4}$, a diferencia de lo que sucede en otros sistemas de nuestro entorno ${ }^{5}$.

En lo que respecta al Gobierno central, la Constitución en su artículo 101 es muy parca a este respecto y no establece las potestades del Ejecutivo en funciones. En el caso de las Comunidades Autónomas, el papel del Gobierno que se encuentra en esta situación es algo que suele venir detallado, con sus atribuciones y límites, en las distintas leyes del Gobierno de las CCAA y que no debería provocar problemas si no fuera porque la interinidad, que es una situación de normalidad democrática, se introduce en el debate político de manera inevitable ${ }^{6}$.

\footnotetext{
2 Artículo 67.3 de la Ley Orgánica 6/2006, de 19 de julio, de reforma del Estatuto de Autonomía de Cataluña.

${ }^{3}$ Es el caso de Andalucía, Cantabria, Canarias, Castila y León, Cataluña, Madrid, Valencia, Extremadura, Baleares, La Rioja, País Vasco, Murcia y Galicia. En el caso del País Vasco, el plazo es de 60 días desde la convocatoria del Parlamento para la investidura.

${ }^{4}$ Asturias y Aragón. Navarra establece el plazo máximo de tres meses desde la celebración de las elecciones.

5 Bélgica ha llegado a estar 541 días con un gobierno en funciones, de junio de 2010 al 6 de diciembre de 2011. No era la primera vez. En 1988, tardaron 150 días y en 2007-2008, nueve meses y medio.

${ }^{6}$ Como sucedió en Andalucía a raíz de las elecciones del 22 de marzo, las funciones y límites del gobierno en funciones saltaron a la opinión pública, llegando a hablarse de paralización de los servicios públicos hasta tanto no se produjera la investidura del titular de la presidencia del Gobierno.
} 
Mucho más grave, a mi juicio, es la parálisis institucional a la que los partidos mayoritarios intentan someter en ocasiones a los Parlamentos, con el argumento de que un Parlamento sin gobierno no puede funcionar ${ }^{7}$. Esta afirmación, que invierte los presupuestos del sistema parlamentario de gobierno, se encuentra incluso en algunos Reglamentos Parlamentarios autonómicos, que únicamente pueden incluir asuntos de urgencia en el orden del día hasta tanto no se haya producido la investidura.

Más allá de la posible inconstitucionalidad de unas previsiones de este tipo, lo cierto es que parecen abundar en el giro presidencialista que la doctrina ha percibido en los sistemas autonómicos de gobierno ${ }^{8}$. Giro presidencialista que en todo caso supone un reforzamiento del papel del Presidente pero que debe dejar intactos los presupuestos del sistema parlamentario de gobierno. Esto es, Parlamento elegido por la ciudadanía y Presidencia del Gobierno elegida por la Asamblea y sujeta, por tanto, a su control.

Como es sabido, el contrapeso de poderes en el sistema parlamentario, lejos de producirse entre el Legislativo y el Ejecutivo, se articula en torno a dos ejes, Gobierno y mayoría que lo apoya por un lado y oposición parlamentaria por otro. Ahora bien, llevar esta concepción al extremo de desdibujar la posición y funciones del Parlamento es algo que no se puede compartir, aun admitiendo las dificultades téóricas que se plantean cuando el Gobierno y el Parlamento no tienen la relación de fiducia propia del sistema parlamentario de gobierno porque se han producido nuevas elecciones.

En las páginas que siguen vamos a abordar la cuestión del Gobierno en funciones, como paso previo al núcleo de este estudio, el papel del Parlamento durante ese tiempo, tratando de descifrar las concretas potestades del Parlamento en este interregno. Por más que resulte habitual, no se puede admitir que el Parlamento sea un mero espectador hasta tanto el Gobierno se constituya formalmente tras la investidura.

7 En Andalucía, las Comisiones Permanentes Legislativas no se pudieron crear hasta el día 2 de julio, a pesar de que el Reglamento Parlamentario de la Cámara andaluza establece un plazo de veinte días desde la sesión constitutiva, que tuvo lugar el 16 de abril. En este caso, el partido mayoritario en el Parlamento se negaba a la constitución de las comisiones como un elemento más de presión para conseguir la investidura de su candidata.

8 «El modelo parlamentario autonómico está mutando de manera acelerada hacía esquemas presidencialistas». Morales Arroyo, J. M., «El alcance de la garantía estatutaria de las instituciones de autogobierno", en Cascajo Castro, J. L. y Martín de la Vega, A., Participación, Representación y Democracia, XII Congreso de la Asociación de Constitucionalistas de España, Tirant lo Blanch, Valencia, 2015, pág. 11. 
De hecho, el nuevo panorama político aparecido tras las elecciones del 20D ha supuesto un giro en esta manera de actuar y nada más constituirse las Cortes Generales, los distintos Grupos Parlamentarios han comenzado a presentar iniciativas parlamentarias, arrojando una nueva visión sobre la centralidad del Parlamento ante la imposibilidad de saber a corto plazo quién o quiénes conformarán el nuevo Ejecutivo y cuándo se constituirá. Quién sabe si el nuevo panorama político va a acabar provocando un reequilibrio de las posiciones respectivas de Parlamento y Ejecutivo, que en los últimos años se había inclinado del lado de este último?.

En las páginas que siguen vamos a estudiar esta cuestión. Antes de ello, unas breves notas sobre el Gobierno en funciones.

\section{EL GOBIERNO EN FUNCIONES}

La Constitución Española, en su artículo 101 CE, establece que «El gobierno cesa tras la celebración de elecciones, en los casos de pérdida de la confianza parlamentaria previstos en la Constitución, o por dimisión o fallecimiento de su Presidente» ${ }^{10}$. En el apartado segundo, destaca que «el Gobierno cesante continuará en funciones hasta la toma en posesión del nuevo Gobierno».

De esta manera, el texto constitucional introduce la prorrogatio, que es «aquel instituto por medio del cual un órgano ya cesado tiene la posibilidad de ejercitar sus poderes, aunque sea de forma limitada, y esto no en virtud de un acto especial que concede la prórroga, sino del Derecho» ${ }^{11}$. No había muchas opciones habida cuenta de que la actividad del Estado no se puede paralizar por el hecho de que el gobierno cese en su actividad.

9 Como ha destacado Álvarez Conde, «La aceptación del fortalecimiento del Ejecutivo y la proclamación del Estado social y Democrático de Derecho implica un cambio sustancial en las relaciones entre el Gobierno y otros órganos constitucionales, no solo el Parlamento, implicando un mayor margen de autonomía de aquel, que trata de conjugar el principio de estabilidad gubernamental y el necesario control parlamentario a través del principio de representación popular», ÁLVAREZ CONDE, E., «El Gobierno en funciones», Documentación Administrativa, 246-247, 1996-1997, pág. 11.

${ }^{10}$ El Anteproyecto de Constitución preveía la continuación del gobierno en funciones cuando el cese se debiera a la celebración de elecciones y únicamente la continuidad de los Ministros, excepcionando al Presidente del Gobierno, en los casos de dimisión o pérdida de la cuestión de confianza.

${ }^{11}$ De la PeÑa Rodríguez, L., «El control parlamentario del Gobierno en funciones a la luz de la Constitución», en Pau i Vall, F. (coord.), Parlamento y control del Gobierno, Aranzadi, Cizur Menor, 1998, pág. 346. La prorogatio fue definida por Tosato durante la elaboración de la Constitución italiana y supone que «un órgano ya cesado pueda continuar ejerciendo, aunque de manera limitada, sus atribuciones, y ello no en virtud de un acto especial que concede la prórroga, sino de derecho». Citado por D’OrAZIO, G, «Considerazione critiche sulla prorrogatio nella organizacione costituzionale italiana», en Rivista Trimestale de Diritto Pubblico, 3, 1980, pág. 819. 
Este instituto, que no es exclusivo del Gobierno ${ }^{12}$, responde a la elemental necesidad de que las cosas sigan funcionando aun cuando el Ejecutivo se encuentre en situación de interinidad ${ }^{13}$, salvaguardando los intereses generales, con un límite: evitar en la medida de lo posible que su actuación pueda condicionar la aplicación del programa del futuro Gobierno ${ }^{14}$.

Como señala Aguiar de Luque, la prorrogatio no permite por sí sola explicar la posición del gobierno en funciones, sino que dos elementos generales matizan dicha situación. Por un lado, la relación fiduciaria inexistente entre el gobierno y el parlamento en el caso del gobierno cesado. Ciertamente, el elemento fundamental del sistema parlamentario de gobierno radica en la confianza que media entre el órgano de representación directa de la ciudadanía, el Parlamento y la Presidencia del Gobierno, investido por aquél. En el caso del Gobierno cesante, esta relación ya no existe, bien porque se ha quebrado tras la no superación de una cuestión de confianza, porque el presidente del gobierno ha dimitido o no puede ya seguir ejerciendo su responsabilidad (muerte, incapacidad). $\mathrm{O}$, el caso más habitual, por la celebración de elecciones.

Por otro, la heterogeneidad, ambigüedad —y amplitud añadiría — de las funciones del gobierno, que sumado a la imposibilidad de utilizar los instrumentos más contundentes de exigencia de responsabilidad — moción de censuraprovocan una curiosa situación en la que el gobierno cesante tiene amplias capacidades de actuación y el parlamento, muy pocos instrumentos de control ${ }^{15}$.

Ciertamente, estos elementos atribuyen a la prorrogatio gubernamental unas características que hacen muy necesario su estudio, desarrollado ampliamente por la mejor doctrina. Supone una limitación de las funciones que sin embargo no siempre se encuentra explícita en los textos normativos. La Constitución, como acabamos de ver, únicamente alude a que el gobierno cesante continúa en funciones.

Como ha sostenido Reviriego Picón, «La continuidad en funciones del órgano gubernamental dibuja en éste una naturaleza diferenciada que se asienta en la finalidad de su actuación, que, recordemos, no es otra diferente que impedir que se produzca una parálisis de la función del gobierno y posibilitar el traspaso de pode-

12 Piénsese en los magistrados del Tribunal Constitucional o en los integrantes del Consejo General del Poder Judicial.

${ }^{13}$ Ya Locke hablaba de la necesidad de que el Poder Ejecutivo se encuentre siempre en funciones. Locke, J., The Second Treatise on Civil Government, Capítulo XIII.

${ }_{14}$ De la PeÑa Rodríguez, L., «El control parlamentario del Gobierno en funciones a la luz de la Constitución», en PAu i Vall, Parlamento y control del Gobierno, Aranzadi, Pamplona, 1998, pág. 347.

15 Aguiar de Luque, L., «La posición del Gobierno cesante o en funciones en el ordenamiento constitucional español», en Garrorena Morales (ed.), El Parlamento y sus transformaciones actuales, Tecnos, Madrid, 1990, págs. 261 y 262. 
res y la formación de un nuevo Ejecutivo. Esto debiera traducirse, teóricamente, y desde consideraciones políticas, en la inhabilitación del mismo para el desarrollo de su programa de gobierno conforme a consideraciones políticas, y la limitación de su actividad a la ordinaria administración de los asuntos públicos con la lógica habilitación -con independencia de tales criterios - para los supuestos en que la urgencia de la medida así lo pudiera hacer preciso; se limita así la acción del Gobierno, condicionando la libertad de sus fines, contenido y formas de actuación» ${ }^{16}$.

El legislador estatal no desarrolló la posición, atribuciones y límites del gobierno cesante hasta 1997, con la aprobación de la Ley 50/1997, de 27 de noviembre, del Gobierno. Todo lo contrario a lo sucedido en el ámbito autonómico, donde las Comunidades Autónomas ejecutaron muy pronto esta tarea, habiendo pasado algunas de ellas por regulaciones diversas hasta la fecha ${ }^{17}$. La regla general, como no podía ser de otro modo, es la atribución del despacho ordinario de los asuntos de su competencia, concepto jurídico indeterminado que tiene su origen en los affaires courantes del Consejo de Estado francés, que limita la actuación del Ejecutivo en aquellos asuntos que pudieran comprometer la acción del futuro gobierno ${ }^{18}$.

No todos los casos de prorrogatio gubernamental son iguales porque no todos vienen provocados por la misma causa. De hecho, puede admitirse la modulación de la actuación de un Gobierno cesante, no sólo por la causa del cese, sino también por la adecuación o inadecuación entre mayoría parlamentaria y composición del Gobierno cesante ${ }^{19}$. En esta línea, señala Revenga cómo «el ejercicio del poder por parte del Gobierno en funciones queda sujeto a límites más o menos reducidos en función de la causa determinante de su cese y en especial de la adecuación o inadecuación entre mayoría parlamentaria (emergente o subsistente tras el cese) y composición del gobierno cesante. No es lo mismo, en efecto, asumir la prórroga de

16 Reviriego Picón, F., El Gobierno cesante o en funciones en el ordenamiento constitucional español, Universidad Carlos III de Madrid-BOE, Madrid, 2003, págs. 199 y 200.

17 Sobre este particular, Reviriego Picón, F., «La regulación del Gobierno en funciones en los ordenamientos autonómicos. A propósito del caso cántabro», ob. cit., pág. 663.

18 Arrêt Syndicat Regional des Quotidiens d'Algerie, de 4 de abril, de 1952 y posteriormente confirmado. En este caso, el Consejo de Estado anuló un decreto de 1946 del Gobierno dimisionario, por considerar que las funciones del mismo debían ceñirse a la administración ordinaria. Ya en la V República, la sentencia del Consejo de Estado de 19 de octubre de 1962 reafirmó la invalidez de los actos que excedían de la capacidad de Gobierno, que debía limitarse a la gestión de los asuntos corrientes.

19 Reviriego Picón, F., «La regulación del gobierno en funciones en los ordenamientos autonómicos. A propósito del caso cántabro», ob. cit., pág. 676. Revenga SÁNCHEZ, M., «El gobierno en funciones», en AAVV, Gobierno y Administración en la Constitución, vol. II, AAVV, Dirección General del Servicio Jurídico del Estado, Madrid, 1988, pág. 1522. 
funciones tras una derrota gubernamental en sede parlamentaria o ante el electorado, que hacerlo, por ejemplo, tras el fallecimiento del Presidente del Gobierno o tras la celebración de unas elecciones en las que el partido o coalición de partidos que sustentaba al gobierno cesante haya conseguido revalidar su mayoría ${ }^{20}$.

En este estudio vamos a centrarnos en el cese del gobierno provocado por la celebración de elecciones, limitando la atención al período que media entre la constitución del nuevo órgano parlamentario y la investidura del presidente del gobierno $^{21}$.

\section{II.1 El Gobierno central en funciones}

La Constitución, en su artículo 101 destaca que «El gobierno cesa tras la celebración de elecciones, en los casos de pérdida de la confianza parlamentaria previstos en la Constitución, o por dimisión o fallecimiento de su Presidente». En el apartado segundo, destaca que «el Gobierno cesante continuará en funciones hasta la toma en posesión del nuevo Gobierno» ${ }^{22}$.

Tras la aprobación de la Constitución y con base en este artículo, la doctrina española se polarizó en torno a dos posturas, la de aquellos que consideraban que el gobierno cesante no estaba limitado en sus atribuciones y los que entendían que sí, que el gobierno en funciones necesariamente tenía cercenadas sus facultades ${ }^{23}$.

La primera interpretación partía de la dicción literal del artículo $101 \mathrm{CE}$, de ese lacónico «el gobierno cesante continuará en funciones hasta la toma de posesión del nuevo Gobierno», para considerar que la Constitución apostaba por la conti-

20 Revenga Sánchez, M., «El Gobierno en funciones», ob. cit., págs. 1521, 1522.

${ }^{21}$ Cabe distinguir tres momentos en las relaciones entre el Gobierno y el Parlamento, con independencia del momento concreto al que se vincule el cese del Gobierno y en consecuencia, el inicio de la prorrogatio gubernamental:

- Un primer período que abarca desde la disolución de las Cámaras hasta la celebración de elecciones. mento.

- Un segundo, desde la celebración de las elecciones hasta la constitución del nuevo Parla-

- Un tercero, que abarca desde la constitución del Parlamento hasta la investidura gubernamental.

${ }^{22}$ Un comentario a este artículo puede consultarse en Satrústegui Gil-Delgado, M., «Artículo 101: El cese del Gobierno y el Gobierno cesante», en Alzaga Villaamil, O., Comentarios a la Constitución Española de 1978, Tomo VIII, Madrid, Edersa, 2006.

${ }^{23}$ Sobre este particular, seguimos a Álvarez CONDE, E., «El Gobierno en funciones», ob. cit., pág. 215 y ss. 
nuidad del gobierno en la totalidad de funciones que la Constitución le otorgaba. Autores del relieve de Alzaga ${ }^{24}$ o Sánchez Agesta compartían esta interpretación ${ }^{25}$.

En el polo opuesto, autores que consideraban que de la Constitución se deducían límites de carácter jurídico para el Gobierno en funciones, que no podría continuar desarrollando su programa de gobierno ${ }^{26}$.

Una tercera vía estaba conformada por aquellos autores, como Santaolalla, Espín Templado o Lucas Murillo de la Cueva, que interpretaban que el Gobierno cesante tenía que enmarcar su actuación en unos contornos precisos de manera necesaria.

La aprobación de la Ley 50/1997, del Gobierno, pondría fin a esta polémica doctrinal acerca de los límites del Gobierno cesante. Su artículo 21 establece que:

«3. El Gobierno en funciones facilitará el normal desarrollo del proceso de formación del nuevo Gobierno y el traspaso de poderes al mismo y limitará su gestión al despacho ordinario de los asuntos públicos, absteniéndose de adoptar, salvo casos de urgencia debidamente acreditados o por razones de interés general cuya acreditación expresa así lo justifique, cualesquiera otras medidas.

4. El Presidente del Gobierno en funciones no podrá ejercer las siguientes facultades:

a) Proponer al Rey la disolución de alguna de las Cámaras, o de las Cortes Generales.

b) Plantear la cuestión de confianza.

c) Proponer al Rey la convocatoria de un referéndum consultivo.

5. El Gobierno en funciones no podrá ejercer las siguientes facultades:

a) Aprobar el Proyecto de Ley de Presupuestos Generales del Estado.

b) Presentar proyectos de ley al Congreso de los Diputados o, en su caso, al Senado.

6. Las delegaciones legislativas otorgadas por las Cortes Generales quedarán en suspenso durante todo el tiempo que el Gobierno esté en funciones como consecuencia de la celebración de elecciones generales».

Así, el modelo central de Gobierno en funciones consiste en atribuirle el despacho ordinario de los asuntos públicos y establecer limitaciones muy concretas: imposibilidad de presentar el proyecto de ley de presupuestos y de pre-

24 Alzaga Villaamil, O., Comentario sistemático a la Constitución española de 1978, Madrid, 1981.

${ }_{25}$ Matizaba sin embargo Sánchez Agesta que en el caso de que la situación del gobierno en funciones venga provocada por una la pérdida de confianza de la Cámara, el Gobierno en funciones únicamente podía resolver asuntos de trámite. SánChez Agesta, L., Sistema político de la Constitución Española de 1978, Editoriales de Derecho Reunidas, Madrid, 1981.

${ }^{26}$ En esta línea, autores como Satrústegui y García Herrera. 
sentar proyectos de ley a las Cortes Generales. También está prohibida la propuesta al rey de un referéndum consultivo.

Más allá de eso, otras limitaciones propias del mismo sistema parlamentario de gobierno, basado en la relación de confianza entre Parlamento y Gobierno: imposibilidad de disolver las Cortes Generales o cualquiera de las cámaras y de plantear una cuestión de confianza. Ello es lógico si reparamos en que en el caso del gobierno en funciones la relación de fiducia no existe. Estas previsiones se aplican al gobierno cesante por cualquier causa, sin reparar en la causa del cese por lo que también rigen en el período que media entre la constitución de la Cámara y la investidura del nuevo titular de la presidencia del gobierno.

De esta manera, la Ley del Gobierno añade poco a la teoría general de la prorrogatio, que limita la gestión del gobierno en funciones al despacho ordinario, impidiéndole tomar decisiones que suponen una toma de postura del Ejecutivo desde el punto de vista político porque para ello no está legitimado. En esta línea, ni proyectos de ley, ni presupuestos ni referéndum consultivo. En definitiva, ninguna decisión que pueda comprometer la actuación del nuevo gobierno una vez investido. En este sentido se pronuncia la misma Exposición de Motivos que destaca que «con base en el principio de lealtad constitucional, delimitando su propia posición constitucional y entendiendo que el objetivo último de toda su actuación radica en la consecución de un normal desarrollo del proceso de formación del nuevo Gobierno».

En la práctica se han planteado dudas con respecto a la posibilidad de conceder indultos o extradiciones, resueltas por la jurisprudencia ${ }^{27}$ o de plantear un conflicto de competencias frente a un acto autonómico ${ }^{28}$.

27 Sentencias del Tribunal Supremo de 20 de septiembre de 2005, en la que se anula la decisión de conceder una extradición y de 2 de diciembre de 2005, en la que se desestima el recurso interpuesto frente a una decisión del Gobierno en funciones de denegar una petición de indulto. También la STS de 28 de mayo de 2013, que desestima un recurso interpuesto contra un Real Decreto y que entendió que podía considerarse que atendía al «despacho ordinario de los asuntos públicos».

${ }^{28}$ En febrero de 2016, el Gobierno de la Nación en funciones planteó un conflicto positivo de competencias ante el Tribunal Constitucional en relación con los arts. 1.1 y 3.3 -apartados 1 y 2 del Decreto de la Generalidad de Cataluña 2/2016, de 13 de enero, de creación, denominación y determinación del ámbito de competencia de los Departamentos de la Administración de la Generalidad de Cataluña, en lo relativo a la creación del Departamento de Asuntos Exteriores, Relaciones Institucionales y Transparencia (en el art. 1.1, en cuanto al inciso relativo a Asuntos Exteriores); y con los arts. 1.1.b) y 20 del Decreto de la Generalidad de Cataluña 45/2016, de 19 de enero, de estructuración del Departamento de Asuntos Exteriores, Relaciones Institucionales y Transparencia. 


\section{II.2 El gobierno en funciones en el sistema autonómico español}

Como ya se ha referido, las Comunidades Autónomas aprobaron muy pronto leyes del gobierno que detallaban, en su mayoría, las causas de cese del gobierno, su posición y límites mientras se encuentra en funciones. De hecho, ya en la década de los ochenta, todas las Comunidades Autónomas habían aprobado leyes de sus respectivos gobiernos, que han ido modificando con el paso de los años. Extremadura incluso ha aprobado una ley que regula específicamente esta cuestión, la Ley 4/2015, de 26 de febrero, de transición entre gobiernos en la Comunidad Autónoma de Extremadura.

También contamos con Comunidades Autónomas que no detallan estos límites, sin que eso signifique, en ningún caso, que el Gobierno en funciones tenga atribuidas las mismas competencias que el Ejecutivo que no se encuentra en esa situación. A mi juicio, la ausencia de previsiones precisas sobre el tema, supone una apuesta por la teoría general de la prorrogatio del Gobierno y sus límites. El Ejecutivo tiene que ceñirse al despacho ordinario de los asuntos, lo que entraña que no puede tomar decisiones de alcance político que vinculen al Gobierno siguiente. Únicamente en casos muy tasados, en los que la urgencia de la situación lo exija, se puede ir más allá de ese despacho ordinario de asuntos.

En las páginas que siguen ofrecemos una clasificación de las Comunidades Autónomas en función de la regulación que han desarrollado a este respecto, ofreciendo seis categorías que van desde aquellas autonomías que no ofrecen especificaciones hasta aquellas otras, como Extremadura, que han regulado la cuestión de manera minuciosa.

a) Comunidades Autónomas sin mención alguna a las atribuciones y límites del Gobierno en funciones.

Cuatro son las Comunidades Autónomas que no establecen disposición alguna relativa a los márgenes de actuación y límites del gobierno cesante: Comunidad Valenciana ${ }^{29}$, Galicia ${ }^{30}$, Islas Canarias ${ }^{31}$ y País Vasco ${ }^{32}$.

29 En la Comunidad Valenciana, la Ley 5/1983, de 30 de diciembre, del Consell, tras establecer las causas de cese del Presidente de la Generalitat, destaca que «continuará en funciones hasta que, producida la nueva elección estatutaria del President, se publique su nombramiento por el Rey en el "Boletín Oficial del Estado"».

30 En Galicia, el artículo 29 de la Ley 1/1983, de 22 de febrero, de normas reguladoras de la Xunta y de su presidencia, señala que «el cese del Presidente de la Xunta comporta el de todos los miembros de la misma. La Xunta cesante continuará en funciones hasta la toma de posesión de la nueva Xunta».

31 En las Islas Canarias, la Ley 1/1983, de 14 de abril, del Gobierno y de la Administración de la Comunidad Autónoma de Canarias destaca, tras detallar las causas de cese del Presidente del Gobierno en el artículo 5, que en el caso de celebración de elecciones, de pérdida de confianza parlamentaria y de dimisión, «el Presidente continuará en funciones hasta que su sucesor haya tomado posesión».

32 La Ley 7/1981, de 30 de junio, sobre «Ley de Gobierno» del País Vasco, destaca en el artículo 13.3 que «el Lehendakari cesante y su Gobierno continuarán en el ejercicio de sus fun- 
En ningún caso puede interpretarse este silencio, que tiene más que ver con ausencia de límites adicionales que con una voluntad deliberada de no imponer límites, como una carta en blanco al Gobierno en funciones. Las características propias del sistema parlamentario de Gobierno, basado en la relación de confianza entre la Asamblea parlamentaria y la presidencia del Gobierno, entraña una serie de limitaciones al Gobierno en funciones, dada la inexistencia de ese vínculo fiduciario. De esta manera, el gobierno en funciones tiene que dedicarse a los asuntos de trámite, hasta tanto no se constituya el nuevo Gobierno. Creo que a pesar de la ausencia de regulación específica de los límites, en ningún caso un gobierno en funciones podría presentar un proyecto de ley y, mucho menos, el proyecto de ley de presupuestos. En las páginas que siguen veremos si esto es así en las Comunidades Autónomas que han optado por establecer límites precisos.

b) Comunidades Autónomas donde solo se establecen límites relativos a la relación de confianza propia del sistema parlamentario de gobierno.

En este grupo se sitúan tres Comunidades Autónomas: Asturias ${ }^{33}$, La Rioja ${ }^{34}$ y la Comunidad de $\mathrm{Madrid}^{35}$, que únicamente aluden a la moción de censura y a la cuestión de confianza.

Otras Comunidades Autónomas, además de a estos dos institutos, impiden la disolución de la Cámara por el presidente del Gobierno en funciones. En todo caso, no creo que haga falta explicitar que el presidente en funciones no tiene la potestad de disolver la Cámara parlamentaria. Es obvio que no puede. La ausencia de previsión tiene más que ver con el no reconocimiento de esta capacidad de los presidentes en los primeros Estatutos de Autonomía que con una toma de posición al respecto.

Entre estos dos grupos de Comunidades Autónomas, los que no contienen mención alguna a las atribuciones y límites del Gobierno en funciones y el que

ciones a fin de garantizar el funcionamiento de la Administración y el adecuado traspaso de poderes hasta la toma de posesión del nuevo Lehendakari (...)».

${ }^{33}$ La Ley 6/1984, de 5 de julio, del Presidente y del Consejo de Gobierno del Principado de Asturias, en el artículo 12.2 establece que «El Presidente en funciones no podrá ser sometido a moción de censura ni podrá plantear cuestión de confianza».

${ }^{34}$ La Ley 8/2003, de 28 de octubre, del Gobierno y de incompatibilidades de sus miembros, destaca en el artículo 11.2 como «El presidente en funciones no podrá ser sometido a moción de censura ni plantear cuestión de confianza».

35 Idéntica regulación a la asturiana se contiene en el artículo 17.2 de la Ley 1/1983, de 13 de diciembre, de Gobierno y de la Administración Pública de Madrid: «El Presidente en funciones no podrá ser sometido a moción de censura ni podrá plantear la cuestión de confianza». 
se limita a establecer la imposibilidad de plantear moción de censura o cuestión de confianza, creo que no hay diferencias de fondo. Como se ha destacado, no pueden utilizarse institutos tendentes a quebrar o renovar una confianza que no existe. Es decir, está claro que el presidente de un Gobierno en funciones no puede disolver la Cámara ni plantear una cuestión de confianza. Tampoco la moción de censura tiene razón de ser cuando la relación de confianza que la sustenta, no existe.

c) Habría un tercer grupo de Comunidades Autónomas que a las limitaciones propias del sistema parlamentario de gobierno, añaden algunas que tienen que ver con la capacidad de estructuración del Gobierno cesante: Navarra y Aragón.

De esta manera, la Comunidad Foral Navarra, además de aludir a la imposibilidad de la Presidencia de ser sometida a una moción de censura y de plantear una cuestión de confianza, señala que no podrá nombrar y cesar Consejeros, ni crear, modificar y suprimir Departamentos ${ }^{36}$. Muy parecida es la regulación aragonesa, que además añade la imposibilidad de disolver las Cortes aragonesas ${ }^{37}$.

Creo que un Gobierno en funciones no puede reestructurar el gobierno, con independencia de la regulación legal contenida. Para empezar, parece incompatible con la esencia del Gobierno en funciones, el nombramiento de nuevos miembros del Gobierno, así como los cambios en la estructura administrativa que depende de él. De la misma manera que el presidente de un Gobierno en funciones no puede disolver la Cámara o someterse a una cuestión de confianza, la remodelación de un gobierno llamado a desaparecer parece algo difícil de admitir.

36 Artículo 28.2 de la Ley 14/2004, de 3 de diciembre, del Gobierno de Navarra y de su Presidente: «El Presidente en funciones ejercerá todas las atribuciones propias del Presidente del Gobierno de Navarra, salvo las relativas al nombramiento y cese de los Consejeros, la creación, modificación y supresión de Departamentos, y el planteamiento de la cuestión de confianza, no pudiendo ser tampoco objeto de una moción de censura». Aragón:

${ }^{37}$ Según el artículo 6.4 de la Ley 2/2009, de 11 de mayo, del Presidente y del Gobierno de

«El Presidente en funciones no podrá ser sometido a una moción de censura y no podrá ejercer las siguientes facultades:
a) Designar y separar a los miembros del Gobierno
b) Crear, modificar o suprimir los Departamentos
c) Disolver las Cortes
d) Plantear la cuestión de confianza». 
d) En el cuarto grupo se incluyen aquellas Comunidades Autónomas que únicamente limitan la actividad del Gobierno en funciones relativa a las potestades legislativas y/o presupuestarias: Castilla y León ${ }^{38}$, Cataluña ${ }^{39}$, Baleares ${ }^{40}$ y Murcia ${ }^{41}$.

En este grupo, por tanto, las únicas limitaciones establecidas consisten en la imposibilidad de presentar proyectos de ley (Castilla y León, Cataluña y Murcia) y/o de aprobar el proyecto de presupuestos (Castilla y León, Cataluña y Baleares) y de hacer uso de una delegación legislativa (Cataluña, Baleares y Murcia).

Resulta curiosa la limitación con respecto a las delegaciones legislativas si tenemos en cuenta que, al menos en el caso de la delegación para hacer un texto refundido, no existe innovación legislativa. No es el caso de la delegación mediante ley de bases para la elaboración de un Decreto Legislativo que regule determinada materia. Con independencia de las diferencias que puedan existir entre ambos tipos de leyes, los distintos textos que contemplan tales limitaciones lo hacen sin atender a los referidos tipos, estableciendo una prohibición general. Ciertamente, ni uno ni otro caso parecen encajar en la categoría de despacho ordinario de asuntos, por exceder del mismo, ni considerarse un supuesto de urgencia.

e) En un quinto grupo, se encontrarían aquellas Comunidades Autónomas que además de cuestiones relacionadas con la fiducia parlamentaria, contienen límites materiales como la incapacidad de presentar proyectos de ley. En esta situación se encuentran Cantabria y Castilla-La Mancha.

38 Artículo 22.2 de la Ley 2/2001, de 3 de julio, del Gobierno y la Administración de la Comunidad de Castilla y León: «No obstante, continuará en funciones hasta la toma en posesión de la nueva Junta, limitándose su gestión al despacho ordinario de los asuntos públicos, absteniéndose de adoptar, salvo casos de urgencia o razones de interés general, cualesquiera otras medidas. En ningún caso podrá aprobar Proyecto de Ley de Presupuestos ni presentar Proyectos de Ley a las Cortes de Castilla y León».

39 «El Gobierno, cuando se halla en funciones, no puede aprobar el proyecto de ley de presupuestos de la Generalidad, ni presentar proyectos de ley al Parlamento, ni dictar decretos legislativos» (art. 27.2 Ley 13/2008, de 5 de noviembre, de la presidencia de la Generalitat y del Gobierno).

40 «El Gobierno en funciones no puede adoptar decisiones que excedan de la gestión ordinaria, exceptuando los supuestos de necesidad urgente y, en consecuencia, no puede hacer uso de las delegaciones legislativas otorgadas por el Parlamento, ni aprobar el proyecto de ley de presupuestos generales del Estado» (artículo 18.4 de la Ley 4/2001, de 14 de marzo, del Gobierno de las Illes Baleares).

${ }^{41}$ Según el artículo 29 puntos 3 y 4 de la Ley 6/2004, de 28 de diciembre, del Estatuto del Presidente y del Consejo de Gobierno de la Región de Murcia, «3. el Consejo de Gobierno en funciones no podrá, en ningún caso, aprobar proyectos de ley, ni presentarlos a la Asamblea Regional. 4. Las delegaciones legislativas otorgadas por la Asamblea Regional quedarán en suspenso durante todo el tiempo en que el Gobierno esté en funciones». 
En Cantabria, además de la imposibilidad de presentar una cuestión de confianza y de someterse a una moción de censura, el Gobierno en funciones no puede presentar proyectos de ley ${ }^{42}$. En Castilla-La Mancha, se prohíbe la presentación de una cuestión de confianza y del proyecto de ley de presupuestos, quedando en suspenso las delegaciones legislativas ${ }^{43}$.

f) El sexto y último grupo estaría conformado por aquellas Comunidades Autónomas que recogen una lista más extensa de limitaciones del Gobierno en funciones, que abarcan desde la imposibilidad de acometer cambios en el Ejecutivo autonómico, a los institutos relacionados con el mantenimiento de la confianza parlamentaria o prohibiciones relacionadas con la presentación de proyectos de ley o del proyecto de ley de presupuestos.

En este supuesto se encuentran dos Comunidades Autónomas, Andalucía y Extremadura. Este último constituye un caso aparte porque es el único que contiene una norma específica para regular la sucesión entre gobiernos, como enseguida veremos.

Andalucía contiene una regulación detallada de la posición y límites del gobierno en funciones, que debe limitarse a facilitar el normal desarrollo del proceso de formación del nuevo Consejo de Gobierno y el traspaso de poderes al mismo, limitándose su gestión al despacho ordinario de los asuntos públicos de su competencia, salvo casos de urgencia o interés general debidamente acreditados ${ }^{44}$.

La Presidencia en funciones de la Junta de Andalucía no podrá ser sometida a una moción de censura, ni plantear una cuestión de confianza. La disolución también está vedada. Tampoco podrá designar o separar a las personas titulares de las Vicepresidencias o de las Consejerías; crear, modificar o suprimir Vicepresidencias o Consejerías ${ }^{45}$.

${ }^{42}$ Artículo 23.3 de la Ley 6/2002, de 10 de diciembre, de Régimen Jurídico del Gobierno y de la Administración de la Comunidad Autónoma de Cantabria: «En ningún caso, el Gobierno en funciones podrá presentar proyectos de ley al Parlamento de Cantabria, someterse a la cuestión de confianza o ser objeto de una moción de censura».

43 Art. 18 de la Ley 11/2003, del Gobierno y del Consejo Consultivo de Castilla-La Mancha: «3. El Consejo de Gobierno en funciones debe propiciar el normal desarrollo del procedimiento de formación del nuevo Consejo de Gobierno, no pudiendo aprobar el Proyecto de Ley de Presupuestos ni someterse a la cuestión de confianza. 4. Las delegaciones legislativas otorgadas por las Cortes de Castilla-La Mancha quedarán en suspenso durante todo el tiempo que el Gobierno esté en funciones, precisando la ratificación de aquéllas cuando la causa de cese sea la celebración de elecciones generales».

44 Artículo 37.3 de la Ley 6/2006, de 24 de octubre, del Gobierno de la Comunidad Autónoma de Andalucía.

45 Artículo 37.4. 
En lo que respecta a otro tipo de limitaciones, el Gobierno en funciones no puede aprobar el proyecto de Ley de Presupuestos ni presentar proyectos de Ley al Parlamento de Andalucía ${ }^{46}$.

El caso extremeño, como decíamos, es diferente a todos los demás porque Extremadura es la única Comunidad que cuenta con una norma específica para regular esta cuestión, la Ley 4/2015, de 26 de febrero, de transición entre gobiernos en la Comunidad Autónoma de Extremadura. Esta norma tiene por objeto el régimen de actuación y las limitaciones en la acción del Gobierno en funciones, medidas concretas sobre el traspaso de poderes y pautas generales para la configuración del nuevo gobierno.

Realmente, los ámbitos en los que la norma introduce limitaciones al gobierno en funciones son los mismos que hemos visto para otras Comunidades Autónomas, aunque el nivel de detalle es mucho mayor. Así, el Presidente en funciones no puede disolver la Asamblea ni plantear cuestión de confianza. Tampoco puede nombrar o separar miembros de la Junta de Extremadura o modificar el número y denominación de las Consejerías. La ley impide también la presentación de proyectos de ley, incluido el de presupuestos y las delegaciones legislativas otorgadas por la Asamblea, deben quedar en suspenso. Por el contrario, sí está prevista expresamente la aprobación de decretos-leyes, siempre que la urgencia lo justifique.

Resultan de interés algunas cuestiones más concretas, que no encuentran reflejo en ninguna otra Comunidad Autónoma, como la imposibilidad de solicitar a la Asamblea que se reúna en sesión extraordinaria, de aprobar o autorizar convenios de colaboración y Acuerdos de cooperación con el Estado y demás Administraciones Públicas o de crear Comisiones Delegadas del Consejo de Gobierno.

También se introduce un capítulo importante de limitaciones que afectan a la suscripción de convenios ${ }^{47}$, a la aprobación de expedientes de contratos ${ }^{48}$, a la concesión de subvenciones $^{49}$, a la aprobación o publicación de convocatorias de

46 Artículo 37.5.

47 «Suscribir convenios con otras entidades públicas o privadas que supongan reconocimiento de obligaciones para la hacienda pública de Extremadura» (art. 5.1.a).

48 «Aprobar expedientes de contratos sujetos a regulación armonizada, salvo los de suministros y servicios. Tampoco podrán aprobarse expedientes de acuerdos marco o de sistemas dinámicos de contratación» (art. 5.1.b).

49 «Conceder subvenciones de forma directa sin convocatoria pública, salvo las que se otorguen conforme a los Planes Anuales a que se refiere la Ley 1/2003, de 27 de febrero, de Cooperación para el Desarrollo» (art. 5.1.c). 
procesos selectivos $^{50}$, a las modificaciones en las relaciones de puestos de traba$\mathrm{jo}^{51}$, al nombramiento de personal eventual ${ }^{52} \mathrm{o}$ a la concesión de honores ${ }^{53}$. De hecho, el artículo 5.2 destaca que «desde el cese del Presidente y hasta la toma de posesión del nuevo gobierno no se podrán nombrar ni separar los altos cargos de la Administración de la Comunidad Autónoma.

No cabe duda de que a pesar de la variopinta regulación autonómica del instituto, todas las comunidades responden al mismo patrón, limitando todo aquello que implica una decisión de alcance político que puede mermar el margen de actuación del gobierno siguiente. Las variaciones son de detalle porque la ausencia de una limitación en una determinada comunidad no implica automáticamente que pueda hacer todo aquello que no esté expresamente prohibido. Habrá que ver caso por caso.

\section{POSICIÓN Y FUNCIONES DEL PARLAMENTO RECIÉN CONSTITUIDO DURANTE LA PRORROGATIO GUBERNAMENTAL}

Tras la celebración de elecciones y la consiguiente constitución de la Cámara parlamentaria, se abre un período de tiempo hasta la investidura del presidente o presidenta del gobierno, período que entre nosotros es limitado, como se ha visto más arriba. Durante ese lapso, el Parlamento recién elegido convive con un Gobierno en funciones, que estará más o menos limitado en función de cada ordenamiento jurídico. En ese punto, como hemos visto, se oscila entre las CCAA que no tienen prevista ninguna limitación, más que aquellas que puedan venir dadas por la propia lógica del sistema parlamentario y las que establecen una regulación con un nivel de detalle más alto. En el caso del Gobierno central, no existen limitaciones al funcionamiento del Ejecutivo más allá de las propias de un sistema parlamentario de gobierno, como se ha visto.

El dato fundamental en este período es que la relación de confianza propia del sistema parlamentario entre la Cámara y la presidencia no se da porque el Gobierno fue investido por una Cámara anterior. Esto nos lleva a preguntarnos si este elemento va a incidir en el funcionamiento de la Cámara parlamentaria — consti-

50 «Aprobar o publicar convocatorias de procesos selectivos de acceso o de provisión de puestos de trabajo, con carácter definitivo en ambos casos, para cualquier categoría de empleado público» (art. 5.1.d).

51 «Aprobar o modificar las relaciones de puestos de trabajo de la Junta de Extremadura o de los distintos entes integrantes del sector público autonómico, salvo modificaciones puntuales en ejecución de sentencia judicial firme» (art. 5.1.e).

52 «Nombrar personal eventual, así como nombrar o contratar personal directivo» (art. 5.1.f).

53 «Conceder honores o distinciones» (art. 5.1.g). 
tución de sus órganos y funcionamiento ordinario en Pleno y Comisiones-. Teniendo en cuenta la necesaria colaboración gubernamental para el desempeño de las potestades parlamentarias, hay que preguntarse si la prorrogatio gubernamental compromete el ejercicio de aquellas. En lo que respecta a la función presupuestaria, parece que sí. El Gobierno cesante no puede aprobar el proyecto de presupuestos. Eso le corresponde a un Gobierno en plenitud de funciones. Más problemas se plantean en relación con la potestad legislativa. Parece claro que la iniciativa legislativa está vetada al Gobierno en funciones pero, ¿puede legislar la Cámara con un Gobierno prorrogado? Y ¿puede controlarse la acción de un Ejecutivo cuyo presidente no ha sido investido por la Cámara que controla? A todas estas cuestiones nos enfrentaremos más adelante. Antes vamos a analizar la posible incidencia en las potestades de autoorganización de las Cámaras parlamentarias.

\section{III.1 Organización interna de las Cámaras}

Ninguna limitación existe en lo que respecta a la designación de los órganos principales de gobierno, Presidencia y Mesa, que tiene lugar el mismo día de la constitución de las Cámaras. Asimismo, los Grupos Parlamentarios, fundamentales para el desempeño de las funciones parlamentarias, se constituyen a los pocos días de la sesión constitutiva de la Cámara de que se trate. Una vez conformados, otros órganos que dependen de los mismos, como la Junta de Portavoces, pueden empezar a desempeñar su labor.

Sin embargo, el proceso de organización y funcionamiento interno de las cámaras no siempre se puede hacer sin trabas a partir de la sesión constitutiva de la Cámara. En ocasiones se paraliza su actividad hasta tanto no se haya producido la investidura.

Para analizar esta cuestión, vamos a centrarnos en un par de elementos que nos van a ofrecer algunas pistas sobre el asunto que tratamos: la previsión de plazos para la constitución de las Comisiones parlamentarias, desligados o no de la investidura gubernamental y la capacidad para incluir otros asuntos en el Orden del Día del Pleno más allá de la investidura de la Presidencia, hasta tanto ésta no se produzca. Porque si el Reglamento Parlamentario condiciona el plazo para la constitución de las Comisiones a la investidura, o no permite incluir en el orden del día asuntos que no sean urgentes, está claro que se está condicionando toda la actividad parlamentaria a la investidura. En este caso, habría que plantearse si una autolimitación de este calibre prevista en el propio Reglamento Parlamentario es fruto de la autonomía parlamentaria o excede de la misma vulnerando la posición y atribuciones del Parlamento como Cámara de representación directa de la ciudadanía. 
a) Constitución de las comisiones parlamentarias

De manera habitual, los Reglamentos Parlamentarios fijan un plazo preciso para la constitución de las Comisiones Permanentes. Lo hace así el Reglamento del Congreso, que fija ese plazo en diez días desde la sesión constitutiva de la Cámara $^{54}$, mientras que en el Senado, el Reglamento deja al Presidente su determinación ${ }^{55}$.

En la mayoría de las Comunidades Autónomas, los Reglamentos Parlamentarios establecen un plazo para la constitución de las Comisiones Legislativas, que habitualmente se hace depender de la sesión constitutiva de la Cámara. Este plazo va desde los diez días de Galicia, Baleares y La Rioja, a los treinta días de Navarra o al mes de las Islas Canarias. Por su parte, Andalucía, Cantabria, Castilla-La Mancha, Castilla León y Madrid, fijan en veinte el plazo y Extremadura y Valencia, en quince. Estos últimos también a partir de la sesión constitutiva.

La importancia de esta cuestión radica en la relevancia de las Comisiones para el funcionamiento de las Cámaras. Las Comisiones, conviene recordarlo, son el lugar habitual donde se desempeña el control parlamentario y resultan imprescindibles para el desarrollo de la función legislativa. Una Cámara que no constituye sus Comisiones es una Cámara prácticamente paralizada. La obligación de constituirlas en un determinado término a partir de la sesión constitutiva indica la voluntad de que el Parlamento pueda funcionar con independencia de la investidura.

En una línea más permisiva se encuentran Aragón, Murcia y País Vasco, cuyos Reglamentos guardan silencio sobre este particular, no estableciendo plazo alguno para la constitución formal de las Comisiones. No creo que podamos deducir sin más, de este hecho que las Cámaras citadas, con la excepción del País Vasco como luego veremos, no puedan constituir Comisiones para empezar a desarrollar sus tareas parlamentarias, sino que el momento preciso se deja a la propia Cámara.

54 Según el artículo 46.3 RC, «3. Las Comisiones Permanentes a que se refieren los apartados anteriores deberán constituirse dentro de los diez días siguientes a la sesión constitutiva del Congreso». Esas Comisiones son las Permanentes Legislativas, reguladas en el art. 46.1 y las de Reglamento, Estatuto de los Diputados y Peticiones, reguladas en el art. 46.2 RC.

55 Para ser más precisos, señalar que el art. 52 del Reglamento del Senado atribuye a la Presidencia de la Cámara la fijación del plazo para designar a los miembros de las Comisiones por los distintos Grupos Parlamentarios, fijando en su art. 53 un plazo de diez días para la constitución de las Comisiones, a contar desde la terminación del plazo fijado por la presidencia para la designación de sus miembros. 
Por último, dos Reglamentos Parlamentarios vinculan el plazo de constitución de las Comisiones a la propia investidura de la Presidencia del Gobierno. Es el caso de Cataluña ${ }^{56}$ y Asturias ${ }^{57}$, que fijan el plazo en los días posteriores a la investidura o toma de posesión del nuevo Ejecutivo. Estos preceptos vinculan así el funcionamiento de la Cámara, vía Comisiones Permanentes Legislativas, imprescindibles para las tareas de control y legislativas, a la existencia de un nuevo Gobierno.

b) Imposibilidad de incluir asuntos en el orden del día

Pero sin duda, el indicador más importante es la restricción para incluir asuntos en el orden del día del Pleno hasta tanto no se haya producido la investidura. Es el caso de Valencia y País Vasco. En el primero, se establece que «mientras la Cámara no haya elegido President de la Generalitat no se podrán incluir en el orden del día otros asuntos, salvo que razones extraordinarias y de urgente necesidad, acordadas por la Mesa y la Junta de Síndics lo aconsejaran ${ }^{58}$.

Idéntico precepto encontramos en el Reglamento de la Cámara vasca, que destaca que «Mientras la Cámara no haya designado al Lehendakari no se podrán incluir en el Orden del Día otros asuntos, salvo que lo aconsejaren razones extraordinarias y de urgente necesidad, apreciadas por la Mesa del Parlamento y la Junta de Portavoces ${ }^{59}$. En este caso además, hay que tener en cuenta la necesidad de que se haya producido la investidura para constituir las Comisiones Legislativas.

Poco sentido tiene en estos dos casos preguntarse acerca del ejercicio de las potestades parlamentarias, dado que ambas Cámaras, en base a su autonomía parlamentaria, han optado por autolimitarse hasta tanto no se produzca la investidura. Cabe plantear en todo caso si esta limitación constituye una dejación de

${ }^{56}$ El artículo 51 del Reglamento del Parlamento de Cataluña establece que «el Pleno del Parlamento, dentro de la semana siguiente a la investidura del presidente o presidenta de la Generalidad, por mayoría absoluta, a propuesta de la Mesa y de la Junta de Portavoces, ha de acordar el número y el ámbito de las comisiones legislativas». En su punto dos: «Las comisiones legislativas han de constituirse dentro de la semana siguiente al acuerdo de creación».

57 El artículo 57.3 del Reglamento Parlamentario de Asturias establece que «Las Comisiones Permanentes Legislativas deberán constituirse dentro de los quince días siguientes a la toma de posesión del Consejo de Gobierno, del acuerdo de creación correspondiente o desde la entrada en vigor de la ley que lo disponga. Las restantes Comisiones deberán constituirse dentro de los quince días siguientes a la sesión constitutiva de la Cámara, del acuerdo de creación correspondiente o desde la entrada en vigor de la ley que lo disponga.

58 Artículo 141 Reglamento Parlamentario valenciano.

59 Artículo 30 del Reglamento del Parlamento vasco. 
funciones incompatible con el diseño del sistema parlamentario de gobierno, en el que el Parlamento elegido por la ciudadanía tiene una función que cumplir. A mi juicio, es de dudosa constitucionalidad que una Cámara decida, en base a su autonomía parlamentaria, paralizar toda su actividad hasta tanto no haya un Gobierno investido. Aun admitiendo la importancia de la investidura como principal tarea del Parlamento en el sistema parlamentario de gobierno, semejante autolimitación excede de lo admisible. La autonomía parlamentaria no puede servir de excusa para enmascarar una dejación de funciones de ese calibre ${ }^{60}$.

Volviendo al tema de las Comisiones, tratándose de los órganos donde se desarrolla la mayor parte del trabajo parlamentario, la opción de esperar a la formación del nuevo Gobierno tiene implicaciones importantes. Las razones prácticas habría que buscarlas en la necesidad prevista en los distintos ordenamientos de que haya adecuación entre la estructura del Gobierno en cuestión y las comisiones legislativas. Lo lógico es esperar hasta tanto se creen para que la correspondencia sea perfecta.

Este argumento de índole práctico no puede hacernos olvidar la naturaleza de la relación Parlamento Gobierno en los sistemas parlamentarios de gobierno, en los que el Gobierno se hace depender del Parlamento y no al revés. El compás de espera al que se somete al Parlamento hasta tanto no haya un gobierno investido, no responde a esa relación y parece esconder la idea de que el Parlamento válidamente constituido sólo está preparado para funcionar una vez que se haya producido la investidura. Aunque no cabe duda de que el cometido más importante del Parlamento, desde el punto de vista político, es precisamente la elección del titular de la presidencia del gobierno, sus funciones van mucho más allá y no pueden condicionarse a ese acto.

Continuando con esta lógica, la pregunta que realmente hay que hacerse es si estos preceptos esconden una auténtica limitación en el papel del Parlamento hasta tanto no se haya elegido la presidencia del gobierno. En las páginas que siguen vamos a tratar de dar respuesta, analizando el alcance de las diferentes funciones parlamentarias.

\section{III.2 Funciones parlamentarias}

a) Potestad legislativa

Admitida como una regla generalmente aceptada que un gobierno en funciones no puede presentar proyectos de ley, con independencia de que esta limi-

${ }^{60}$ Sobre la autonomía parlamentaria puede consultarse, GómEz CORONA, E., La autonomía parlamentaria en la práctica constitucional española, Tirant lo Blanch, Valencia, 2008. 
tación esté expresamente recogida, resta por averiguar si está facultado para intervenir en el procedimiento legislativo mediante la fijación de su criterio, contrario o no a la toma en consideración o incluso, a manifestar su consentimiento a determinadas proposiciones de ley que afecten al presupuesto en vigor.

En principio, nada impide en un Parlamento válidamente constituido, el ejercicio de la iniciativa legislativa a sus diputados o diputadas. Otra cosa será la posibilidad de incluir la toma en consideración en el orden del día —algo que no podrá suceder en Valencia y País Vasco- o el traslado de la iniciativa a la Comisión Legislativa Permanente si se toma en consideración la proposición de ley. En los Parlamentos que asocian el plazo de su constitución a la investidura, cabe presumir que estas Comisiones Legislativas no estarán constituidas.

Salvados estos obstáculos, en aquellos ordenamientos en los que no existan, cabe preguntarse si el Gobierno en funciones está facultado para mostrar su criterio con respecto a la toma en consideración y, si le resulta posible otorgar su conformidad a la tramitación si la ley implicara aumento de gasto o disminución de ingresos en el ejercicio presupuestario en vigor. Estas limitaciones presupuestarias de las Cámaras en la aprobación del Presupuesto, han acabado extendiéndose al ejercicio de la potestad legislativa ${ }^{61}$.

En lo que respecta al primer punto, el criterio de un gobierno cesante, poca importancia puede tener a la hora de manifestar su acuerdo o no con el desempeño de la potestad legislativa de las Cámara. Sin embargo, esta afirmación podría extenderse al criterio de un Gobierno válidamente constituido. Poco valor tiene el criterio del Gobierno si la mayoría parlamentaria decide aprobar la ley. Es únicamente un trámite.

Sentado esto, la pregunta es si el criterio del gobierno es determinante y si concluimos que así es, si un Gobierno en funciones podría emitirlo. A mi juicio, el Gobierno en funciones está facultado para mostrar su criterio conforme o no la tramitación de determinada proposición de ley. Es cierto que se trata de un Gobierno con el que la Cámara no tiene relación de confianza y que el criterio es político, no técnico, pero la nula capacidad de vincular, la imposibilidad de influir de alguna manera en el procedimiento legislativo hace que se encuentre entre las funciones asumibles por un Ejecutivo prorrogado. En definitiva, se

${ }^{61}$ A pesar de que esta exigencia plantea problemas de constitucionalidad notables, lo cierto es que se ha generalizado y a día de hoy, el Ejecutivo tanto estatal como autonómico tiene la facultad de rechazar la tramitación de iniciativas legislativas que supongan aumento del gasto o disminución del presupuesto en vigor. Sobre este particular puede consultarse mi trabajo, «Limitaciones financieras de las Cortes Generales, autonomía parlamentaria y pluralismo político», en García Roca, F. J. y Albertí Rovira, E. (coords.), Treinta años de Constitución, Tirant lo Blanch, Valencia, 2010, págs. 939-952. 
trata de un trámite más en el cual el Ejecutivo emite su parecer con respecto a una iniciativa que emana del Parlamento y que va destinado a la Cámara.

Muy distinta es la situación en el caso de la iniciativa legislativa con textos que afecten al presupuesto en vigor. La exigencia de la aquiescencia gubernamental, basada en la cualidad del Gobierno como ejecutor del presupuesto, sólo debe prestarse por un gobierno en plenitud de facultades y no en el caso de un ejecutivo en funciones. En este supuesto, además, el criterio del Gobierno es determinante, dado que se considera que sin esa aquiescencia, la Cámara legislativa no puede aprobar la ley.

¿Puede un Gobierno en funciones decidir si la Cámara recién elegida y constituida tramita una norma que altera el presupuesto en vigor? En otras palabras, ¿puede un Gobierno cesante impedir el ejercicio de la potestad legislativa que afecta al presupuesto en vigor? A mi juicio, no. Aunque sobre este particular no se pronuncie ninguna norma, una decisión como ésta, que coarta la potestad legislativa de la Cámara en base precisamente a que altera las cuentas, no debe tomarse por un Gobierno en funciones. La opción de permitir o no su tramitación es una cuestión netamente política y dependerá del programa y de las prioridades del Ejecutivo. Permitir que un Ejecutivo cesante coarte la potestad legislativa de la Cámara carece de sentido.

Sin embargo, dada la necesidad de contar con este consentimiento, la disyuntiva no es fácil: o se coarta la potestad legislativa de la Cámara porque el Gobierno está en funciones y no tiene capacidad para adoptar esa decisión o se considera que esta potestad entra dentro del despacho ordinario de asuntos y asumimos que un Gobierno en funciones pueda coartar la capacidad legislativa del parlamento negándose a la tramitación de una ley que entrañe aumento de gasto o disminución de ingresos.

En mi opinión, lo más lógico a la vista de estos argumentos, es pensar que antes de la investidura gubernamental, los parlamentarios no pueden desempeñar su labor si el texto legislativo implicara aumento de gasto o disminución de ingresos. En otro caso, si se tratara únicamente de normas que no afectan al presupuesto en vigor, la cuestión sería más sencilla, dado que el Gobierno únicamente tiene que manifestar su criterio.

En definitiva, la ausencia de un Gobierno elegido por la Cámara recién constituida va a influir en el ejercicio de la potestad legislativa, impidiendo legislar en aquellos supuestos en que la aprobación de la ley implique aumento de gasto o disminución de ingresos. No en otro caso. La razón estriba en el importante papel que el Gobierno desempeña en la elaboración y ejecución de los Presupuestos, tanto que se le ha concedido la última palabra en la aprobación de aquellas leyes que pudieran alterar el plan de ingresos y gastos en vigor. 


\section{b) Función presupuestaria}

La Constitución en el Título VII, Economía y Hacienda, atribuye al Gobierno la elaboración de los Presupuestos y a las Cortes Generales, su examen, enmienda y aprobación. A pesar de la aparente claridad del precepto, son muchos los interrogantes que se suscitan. Interrogantes que hacen referencia al complejo entramado de relaciones Ejecutivo-Legislativo en el sistema parlamentario. Como ha destacado Rodríguez Bereijo, estudiar el Presupuesto es penetrar en el fondo de los problemas constitucionales y, particularmente en los regímenes democráticos con separación de poderes, es plantearse el estudio de las relaciones entre el Poder Legislativo y el Poder Ejecutivo ${ }^{62}$.

Esta distribución de tareas entre Gobierno y Parlamento, que se reproduce a nivel autonómico, no puede esconder el protagonismo indiscutible del gobierno en el desempeño de la potestad presupuestaria. Como se ha visto, el Gobierno en funciones no puede presentar el proyecto de ley de presupuestos. Y no puede aunque el ordenamiento jurídico guarde silencio al respecto. En ningún caso puede considerarse la elaboración del proyecto de presupuesto como despacho ordinario de los asuntos públicos. De hecho, difícilmente encontraremos una acción que comprometa más al Gobierno futuro.

c) Función de control de la acción del Gobierno

En el caso de la función de control, las cosas no resultan sencillas. Para empezar, esta potestad tiene su fundamento en la relación de confianza entre la Cámara y la presidencia, propia de los sistemas parlamentarios de gobierno. Sucede que, en el caso que nos ocupa, con una presidencia todavía no investida, esa relación es inexistente. Y lo es porque durante ese lapso de tiempo, la Cámara que le dio su confianza ha terminado su mandato, así como el propio Ejecutivo, que sólo continúa en funciones. Sin embargo y paradójicamente, el control es más necesario que nunca, pues el gobierno cesante tiene limitadas sus atribuciones al despacho ordinario de los asuntos.

Limitar el control parlamentario porque el Gobierno está en funciones, aunque tiene sentido desde los presupuestos clásicos del sistema parlamentario de gobierno, porque la relación de confianza en que se fundamenta ese control no existe, no parece lo más oportuno. Sobre todo si, como se ha visto, esa situación se prolonga.

62 Rodríguez Bereijo, A., «La limitación de la iniciativa parlamentaria en materia presupuestaria en el Derecho Positivo español», Revista de la Facultad de Derecho de la Universidad de Madrid, vol. XII, 33, 1968, págs. 439 y 440. 
Incluso en el caso de un posicionamiento claro a favor del ejercicio de esa función, las dificultades de su aplicación son muchas. Para empezar porque en algunos Parlamentos, como se ha visto, la constitución de las comisiones permanentes no se lleva a cabo hasta la investidura. A ello cabe añadir las dos Comunidades Autónomas, Valencia y País Vasco, en las que no se puede incluir ningún asunto en el orden del día del Pleno.

Siguiendo la lógica del sistema parlamentario de gobierno, las Cámaras no deberían controlar al Gobierno cesante en funciones. Sin embargo, esta afirmación provoca una paradoja difícil de explicar: el Gobierno en funciones, que no puede ejercer todas sus atribuciones, a su vez, está menos supervisado que nunca puesto que no se puede ejercer control político sobre el mismo ${ }^{63}$. De esta manera, existe un largo período de tiempo, desde el cese de la Cámara anterior, hasta la toma de posesión del nuevo Gobierno, en el que el gobierno en funciones no está sometido al control político de su acción.

A mi juicio, esta afirmación requiere alguna matización. Siendo cierto que el presupuesto sobre el que se sustenta la función de control parlamentario del Gobierno no existe, la relación de fiducia, también lo es que un Parlamento recién constituido debería gozar de plena legitimidad para valorar políticamente las actuaciones del Ejecutivo en funciones, que tiene que ceñirse a unos límites más estrictos que si estuviera en plenitud de facultades. El Parlamento, como órgano de representación y debate de la ciudadanía no puede verse coartado en su posición constitucional por el hecho de que el nuevo gobierno no haya sido investido. En consecuencia, los grupos parlamentarios pueden solicitar la comparecencia de los miembros del Gobierno para que expliquen su actuación como gobierno en funciones. Pero, ¿qué sucede con preguntas e interpelaciones, el método más habitual de control?

El quid de la cuestión debería estar en el momento en el que se ha desempeñado la actividad que se pretende controlar. No tiene sentido preguntar a un Gobierno en funciones sobre la política que ha llevado a cabo en un momento anterior a las elecciones porque la ciudadanía ya ha ejercido su control más efectivo: el derecho de voto, validando o no esa actuación. Sin embargo, los instrumentos habituales de control pueden resultar de utilidad siempre y cuando se utilicen para supervisar la actuación del gobierno en funciones, a fin de constatar si se ha ceñido a los límites propios de la prorrogatio ${ }^{64}$.

${ }^{63}$ Únicamente el control de la jurisdicción contencioso-administrativa en aquellos supuestos en que sea posible por no tratarse de actos netamente políticos.

${ }^{64}$ En este sentido se pronuncia De la PeÑa Rodríguez, que destaca que «sólo resultaría susceptible de fiscalización la actividad del Ejecutivo, referida a la gestión de asuntos de trámite y urgentes durante el período de interinidad, excepto que el Gobierno hubiera rebasado tales límites». 
En esta línea, De la Peña señala dos criterios para las iniciativas de control: «En primer lugar, aquellas que se dirigen estrictamente al Gobierno en funciones y, por otro lado, las que tienen como destinatario al nuevo Ejecutivo. Una vez cumplidos los requisitos reglamentarios, las primeras podrían tramitarse en la forma y en los plazos previstos por el Reglamento para los casos habituales, correspondiendo al autor de este tipo de iniciativas la valoración de su eficacia, incluyendo su posible caducidad una vez que el nuevo Gobierno tome posesión. El segundo tipo de iniciativas de control, siempre que reúnan los requisitos reglamentarios, se admitirá a trámite con la peculiaridad de que no se remitirían al Gobierno en funciones, dado que éste no es su destinatario, sino que se enviarían al nuevo Gobierno, a partir del momento en que toma posesión. La consecuencia práctica sería que los plazos reglamentarios, en este caso, se computarán a partir de la fecha de su toma de posesión, coincidente con la de su remisión. De esta forma se cohonestarían la necesidad de mantener un control del Ejecutivo en funciones y la remisión de estas iniciativas al destinatario auténtico de las mismas» ${ }^{65}$.

Más necesaria aún es la intervención del Parlamento, a través de los instrumentos de impulso político o indirizzo, en aquellos supuestos en que el Gobierno en funciones tenga que afrontar alguna cita insoslayable, como la participación en una cumbre europea, o en el caso de los Ejecutivos autonómicos, la celebración de alguna Conferencia Sectorial. No cabe duda de que ese hecho puede suponer una extralimitación por cuanto la manifestación de voluntad finalmente aprobada acabará provocando efectos políticos en el nuevo gobierno. Sucede sin embargo que no es posible renunciar a ellas.

Estos casos presentan unas características peculiares que podrían requerir la participación del Parlamento en la conformación de la voluntad que el Gobierno debe expresar ante las instancias europeas. Cabe pensar en consecuencia que en este caso, el Gobierno aun cuando esté teóricamente capacitado, no debería participar en ningún debate europeo sin escuchar lo que la nueva Cámara tiene qué decirle. Para ello, las Cámaras podrían recurrir a la función de impulso político o indirizzo. Veámoslo con más detenimiento.

\section{d) Función de impulso}

Aunque la Constitución no menciona para nada entre las potestades de las Cortes Generales, la de orientación política no son pocos los autores que, por influencia de la doctrina italiana, reconocen la existencia de la función de indirizzo o impulso

${ }^{65}$ De la PeÑa Rodríguez, L., «El control parlamentario del Gobierno en funciones a la luz de la Constitución», en Pau i Vall, Parlamento y control del Gobierno, Aranzadi, Pamplona, 1998, pág. 347. 
político $^{66}$. Muchos Estatutos de Autonomía se han hecho eco de esta teoría e incluyen entre las funciones de sus respectivas Asambleas la de orientación política ${ }^{67}$.

La función de impulso político permite a las Cámaras exigir al Ejecutivo que adopte determinada decisión en función del criterio por ellas marcado. Aunque el incumplimiento no lleva aparejado sanción alguna, resulta evidente que un pronunciamiento del Parlamento debería hacer alguna mella en la actuación del Ejecutivo, sobre todo si se encuentra en funciones.

¿Puede exigir el Parlamento recién constituido al gobierno en funciones que actúe de determinada manera? Una vez más, la inexistencia de la relación de confianza propia del sistema parlamentario de gobierno obliga a matizar la respuesta, aunque a nuestro juicio, en la función de impulso, lo relevante no es esa relación de fiducia sino la legitimidad que otorga al Parlamento el encontrarse en su mandato y no haberlo concluido. En otras palabras, lo relevante para ejercer esta función de impulso político es la propia posición del Parlamento y no la del Ejecutivo, que puede estar o no en funciones.

Los días 18 y 19 de febrero de 2016, el Presidente del Gobierno en funciones, Mariano Rajoy, acudió a una Cumbre europea en la que se debatían asuntos de tanta relevancia como la oferta realizada a Reino Unido para que no abandonara la UE o la posición europea sobre la llegada de refugiados. En estos casos, lo habitual es que el Presidente del Gobierno comparezca después de la Cumbre, mientras que el Secretario de Estado competente, lo hace de manera previa en la Comisión Mixta para la Unión Europea. Sin embargo, el dato nada desdeñable de que el Presidente del Gobierno se encontrara en funciones, unido a que la composición de la Cámara en nada se parece a la anterior, obliga a reconsiderar esa costumbre. Pocos casos vamos a encontrar en los que tenga tanto sentido que los Parlamentos se pronuncien acerca de la posición que el Gobierno debería adoptar en la cita europea. Lo habitual en un caso así debería ser la comparecencia del jefe del Ejecutivo a petición propia pero en caso de no ser así, el Parlamento no sólo puede, sino que debe, solicitar la comparecencia o incluso adoptar alguna resolución en la que se fije la postura que debe defender el Gobierno español.

La explicación radica en que en estos casos asistimos a la paradoja de que el Gobierno en funciones se ve obligado a adoptar decisiones que tienen implicaciones políticas que van más allá de la mera gestión ordinaria de los asuntos públicos.

${ }^{66}$ Sobre este particular puede consultarse Pitarch, I. E., «La función de impulso político en los Parlamentos de las Comunidades Autónomas», en El Parlamento y sus transformaciones actuales, ob. cit., págs. 311-335.

${ }^{67}$ En este sentido, los Estatutos de Andalucía (art. 106.2), Asturias (art. 23.1), Cantabria (art. 8.1), Castilla y León (art. 24.2), Extremadura (art. 16.2. h), Madrid (art. 9), Navarra (art. 11), Aragón (art. 33.1), Cataluña (art. 55.2), La Rioja (art. 16.1), del País Vasco (art. 25) y Murcia (art. 22). 
No cabe duda de que, si nos ceñimos a los estrictos márgenes de actuación de los gobiernos en funciones, la manifestación de voluntad que va a permitir a una institución europea manifestar una posición que acabe vinculando a todos los Estados miembros de la UE, queda fuera de ese margen. Sin embargo, las instituciones europeas tienen sus propios ritmos, que no pueden detenerse cada vez que un Estado miembro se encuentre en el trance de formar nuevo Gobierno.

En consecuencia, el Gobierno central en funciones puede verse obligado a acudir a un evento, contradiciendo las mismas bases de la prorrogatio gubernamental. ¿Qué hacer en ese caso? Activar los mecanismos de información e impulso parlamentarios. Solo así podremos cumplir nuestras obligaciones, además de vigilar al Gobierno en el desempeño de una tarea que difícilmente encaja en los límites de actuación de un gobierno en funciones.

De esta manera, aunque es cierto que con la celebración de nuevas elecciones se ha roto el vínculo entre el Parlamento y el Ejecutivo y que este vínculo no se restablecerá hasta tanto sea investida la nueva presidencia del Gobierno, las nuevas realidades obligan a matizar las mismas posibilidades del Parlamento de plantear cuestiones de indirizzo político a un Ejecutivo que no sostiene.

Más que una posibilidad, en un caso como el analizado, se trata de una exigencia. La única manera de paliar la falta de legitimidad de un Gobierno en funciones para adoptar decisiones que, aunque inevitables en el tiempo, vincularán al Ejecutivo entrante, es que sea la propia Cámara la que fije esa posición.

Esta situación que se da con la Unión Europea es extrapolable al sistema autonómico si pensamos, por ejemplo, en la celebración de una Conferencia Sectorial en la que se adoptan importantes decisiones. La participación de un gobierno en funciones, con una postura diversa a la mantenida por la mayoría de la Cámara, es una situación rechazable que habría que evitar a toda costa. La existencia de institutos apropiados para subsanar estos problemas, como los pronunciamientos a través de proposiciones no de ley, mociones o resoluciones permiten evitar estos problemas.

\section{CONSIDERACIONES FINALES}

El Parlamento recién constituido tras la celebración de elecciones y en el período que media hasta la investidura gubernamental no puede ver limitada su actividad más que en aquellas cuestiones en las que se requiere un gobierno en plenitud de funciones. En esta línea, el ejercicio de la potestad presupuestaria así como el de la potestad legislativa con incidencia en el presupuesto en vigor 
se ven necesariamente afectados. Asimismo, la función de control del Gobierno, basada en una relación de confianza que en este supuesto no existe, se ve alterada hasta el punto de que la nueva Cámara no puede fiscalizar la actividad gubernamental anterior a las elecciones.

Esto no significa que el Parlamento deba asistir como un mero espectador a la actuación del gobierno en funciones. Por la propia naturaleza de la prorrogatio, que debe limitarse a la gestión de los asuntos ordinarios y de mero trámite, el Parlamento tiene la obligación de controlar la actuación de un Ejecutivo que no cuenta con el respaldo parlamentario. De esta manera, podrá controlar al Gobierno en funciones, así como ejercer la potestad legislativa con repercusiones financieras en futuros ejercicios presupuestarios.

Una función que cobra especial protagonismo en esta situación es la de impulso u orientación política, a través de la cual el Parlamento puede establecer líneas de actuación del Gobierno cesante y que cobra todo el sentido cuando la composición de la Cámara salida de las urnas difiere de la anterior.

La actividad parlamentaria producida en el Congreso de los Diputados tras la celebración de las elecciones del 20-D parece ir en esa dirección. El cambio de escenario producido en las últimas elecciones celebradas en nuestro país está provocando una revitalización de la posición y funciones del Parlamento que en los últimos años se había convertido en cámara de ratificación de las decisiones adoptadas por Ejecutivos fuertes y ampliamente respaldados por las urnas. La actuación de las Cortes Generales en la brevísima XI Legislatura así lo pone de manifiesto. Podríamos estar ante el primer síntoma del nuevo papel que el Parlamento parece llamado a ocupar en la escena política actual.

Title:

THE LIMITATIONS OF THE NEWLY ELECTED PARLIAMENT DURING THE EXTENDED MANDATE OF THE CARETAKER GOVERNMENT

\section{Summary:}

I. Preliminary. II. Outgoing government. II.1 Outgoing state government. II.2 Outgoing autonomic government. III. The limitations of the new elected Parliament during the extended mandate of the caretaker government. III.1 Internal proceedings. III.2 Parliamentary functions. IV. Concluding remarks 


\title{
Resumen:
}

Mucho se ha escrito sobre el sentido y las limitaciones del gobierno en funciones, instituto necesario porque la labor de gobierno no puede paralizarse por la sucesión natural de titulares al frente del mismo. El recurso a la prorrogatio de los órganos constitucionales sigue siendo válido para explicar este fenómeno.

Menos interés ha suscitado el papel del Parlamento válidamente constituido tras la celebración de elecciones, en el tiempo que media entre esa constitución y la investidura del titular de la Presidencia del Gobierno.

En las páginas que siguen abordaremos esta última cuestión, tratando de dilucidar si el sistema parlamentario de gobierno presente entre nosotros también en las Comunidades Autónomas introduce alguna variante en el funcionamiento parlamentario, más allá del derivado por las propias limitaciones gubernamentales del Ejecutivo en funciones.

\begin{abstract}
:
Much has been written about the sense and limitation of the caretaker Government, deemed a necessary body since the governmental tasks may not be paralyzed due to the natural succession thereof. Resourcing to an extension (prorrogatio) of the mandate of constitutional bodies as caretakers still stands as a valid explanation of this phenomenon. The role of the Parliament validly constituted through elections during the vacatio leading to the appointment of the new president has attracted less interest. This work aims at addressing this understudied issued in an attempt to elucidate whether the Spanish parliamentary system of government, operating both at the State and regional levels, introduces any variant in the functioning of the Parliament beyond the common limitations of the caretaker Government.
\end{abstract}

Palabras clave:

Gobierno en funciones; elecciones; sistema parlamentario de gobierno.

Keywords:

Caretaker government; elections; parliamentary system of government. 
